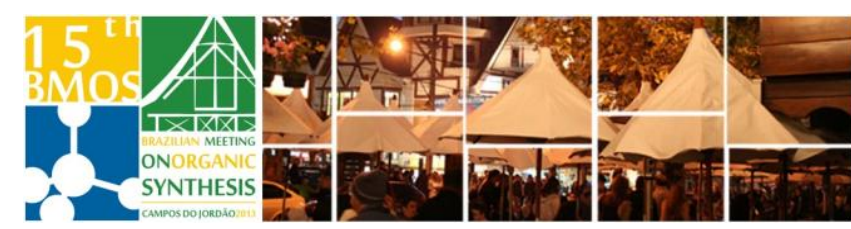

\title{
Preparation of New Magnesium Carbenoids Aiming Inhibitors of HIV-1 Protease Synthesis
}

\author{
Nishimura, R. H. V.; Toledo, F. T.; Clososki, G. C.* \\ Research Center for Natural and Synthetic Products - FCFRP-USP \\ Ribeirão Preto - Brazil \\ *gclososki@yahoo.com.br
}

Keywords: Inhibitors of HIV-1 protease, magnesium carbenoids, chlorohydrins.

\section{INTRODUCTION}

Inhibitors of HIV-1 protease were developed to act specifically on this enzyme class, with high affinity and high complementarity to the catalytic site of the protein, intrinsically competing with the natural substrates. ${ }^{1}$ The (2S,3S)-N-Boc-3-amino-1,2-epoxy4-phenylbutane (1) and its diastereomer of configuration $(2 R, 3 S)(2)$ are key intermediates in the preparation of some important antiretroviral compounds such as saquinavir, amprenavir, atazanavir and lopinavir. ${ }^{2}$
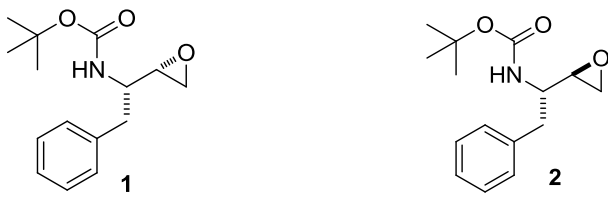

Thus, in this work we have investigated a new method for the stereoselective preparation of these chiral intermediates using organomagnesium reagents complexed with lithium chloride.

\section{RESULTS AND DISCUSSION}

Initially, we studied the preparation of the mixed lithium-magnesium carbenoid $\mathrm{ClCH}_{2} \mathrm{MgCl}$.LiCl (3) through the reaction between chloroiodomethane (4) and $i$-PrMgCl.LiCl (5) (turbo Grignard). ${ }^{3}$ The best reaction conditions were determined by the reaction of magnesium carbenoid and benzaldehyde leading to the corresponding chlorohydrin in $90 \%$ yield (Scheme 1).

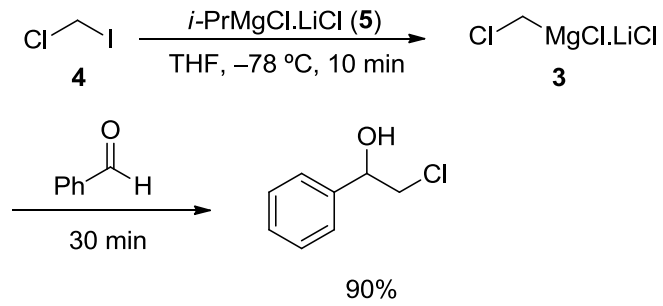

Scheme 1

The reagent 3 works well with different types of aromatic, aliphatic and heterocyclic aldehydes, leading to the formation of the corresponding chlorohydrins in good yields (Scheme 2).

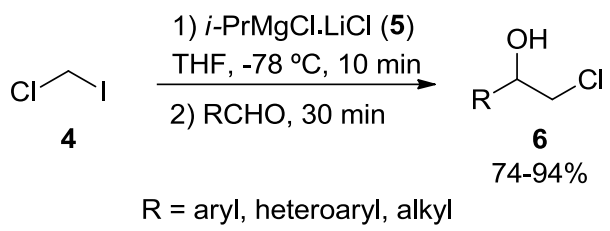

Scheme 2

In recent studies the reagent of type $\mathbf{3}$ was tested with the aldehyde derivative of $L$-phenylalanine (7) leading to the corresponding chlorohydrins (8), in a good diastereomeric excess (determined by LC-MS analysis).

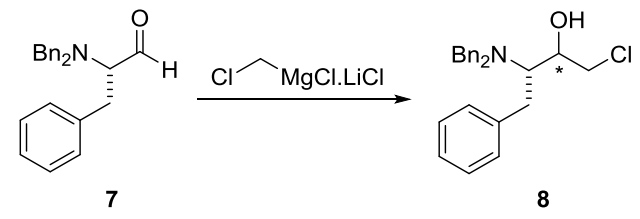

Scheme 3

The absolute configuration of the synthesized compounds is now under investigation by Nuclear Magnetic Ressonance (NMR).

\section{CONCLUSION}

Chloromethylmagnesium compounds of type $\mathbf{3}$ are very selective reagents and show a great potential for preparation of chlorohydrins. Furthermore, it can be an alternative to the synthesis of important intermediates of inhibitors of HIV-1 protease.

\section{ACKNOWLEDGEMENTS}

Authors thank CAPES, FAPESP and CNPq for financial support.

\section{REFERENCES}

${ }^{1}$ Wensing, A. M. J.; van Maarseveen, N. M.; Nijhuis, M. Antivir. Res. 2010 85, 59.

${ }^{2}$ Beaulieu, P. L.; Wernic, D. J. J. Org. Chem. 1995, 90, 6696.

${ }^{3}$ Krasovskiy, A.; Knochel, P. Angew. Chem. Int. Ed. 2004, 79, 14 $15^{\text {th }}$ Brazilian Meeting on Organic Synthesis - 15 $5^{\text {th }}$ BMOS - November 10-13, 2013 - Campos do Jordão, Brazil 